\title{
An Overview of Elevated Temperature Damage Mechanisms and Fatigue Behavior of a Unidirectional SCS-6/Ti-15-3 Composite
}

Michael G. Castelli

Sverdrup Technology, Inc.

Lewis Research Center Group

Brook Park, Ohio

and

John Gayda

National Aeronautics and Space Administration

Lewis Research Center

Cleveland, Ohio

Prepared for the

Tenth Biennial Conference on Reliability, Stress Analysis and Failure Prevention sponsored by the American Society of Mechanical Engineers

Albuquerque, New Mexico, September 19-22, 1993 


\title{
AN OVERVIEW OF ELEVATED TEMPERATURE DAMAGE MECHANISMS AND FATIGUE
}

\section{BEHAVIOR OF A UNIDIRECTIONAL SCS-6/Ti-15-3 COMPOSITE}

\author{
Michael G. Castelli \\ Sverdrup Technology, Inc. \\ Lewis Research Center Group \\ Brook Park, Ohio 44142 \\ and \\ John Gayda \\ National Aeronautics and Space Administration \\ Lewis Research Center \\ Cleveland, Ohio 44135
}

\section{SUMMARY}

The fatigue behavior of a unidirectionally reinforced titanium matrix composite (TMC), SiC/Ti-15-3, was thoroughly characterized to support life prediction modeling of advanced TMC disks designed for gas turbine engine applications. The results of this coupon-level experimental investigation are reviewed in this paper. On a stress basis, the isothermal fatigue behavior of the $\left[0^{\circ}\right]$ TMC revealed significant improvements over the unreinforced matrix. In contrast, the $\left[90^{\circ}\right] \mathrm{TMC}$ exhibited degraded properties and lives for similar comparisons. This was attributed to the weak fiber/matrix interfacial bond. Encasing the $\left[0^{\circ}\right]$ TMC with a Ti-15-3 case did not affect isothermal fatigue lives at higher strain levels. However, at lower strain levels, rapid initiation and propagation of large fatigue cracks in the case degraded the fatigue lives. Thermomechanical fatigue (TMF) lives were significantly reduced for the $\left[0^{\circ}\right]$ TMC when compared to isothermal lives. At high strains, in-phase TMF produced extremely short lives. This degradation was attributed to fiber overload failures bought about by stress relaxation in the matrix. At low strains, outof-phase TMF conditions became life-limiting. Environment-assisted surface cracking was found to accelerate fatigue failure. This produced extensive matrix damage with minimal fiber damage. For the $\left[90^{\circ}\right]$ TMC, TMF conditions did not promote an additional degradation in cyclic life beyond that observed under isothermal conditions.

\section{INTRODUCTION}

Performance and thrust-to-weight goals of advanced gas turbine engine designs require significant advances in material capabilities. It is anticipated that many of these advances will be enabled through the use of titanium matrix composites (TMCs) which offer high strength/density ratios. One potential use of TMCs is in advanced compressor rotor designs where TMC reinforcement rings are embedded within integrally bladed rotors. Such designs offer attractive benefits including both weight reductions and increased rotor speeds over conventional nickel and titanium rotors. However, before the benefits of introducing TMCs into such designs can be fully realized, several key issues including component design, fabrication, inspection, and predictions of structural behavior must be addressed and demonstrated.

To this end, NASA and Pratt \& Whitney (P\&W) Aircraft Division entered into a cooperative research program with the goal of developing and verifying fatigue life prediction models for metal matrix composites, and in particular, TMCs. Emphasis was placed on ultimately modeling the static burst and cyclic fatigue lives of subscale TMC reinforcement rings which were representative of those used in advanced compressor rotor designs. To support and guide the fatigue life modeling effort, a coupon-level experimental 
program was established with the goal of providing the necessary characterization data for the selected TMC system, namely (SiC)SCS-6/Ti-15-3. The fatigue work conducted at NASA Lewis Research Center in support of this experimental program is the focus of this paper.

The objective of this study was to thoroughly characterize the fatigue behavior and damage mechanisms of a unidirectionally reinforced SCS-6/Ti-15-3 composite. Although the SCS-6/Ti-15-3 system is not of primary interest for gas turbine engine applications (due to limitations associated with the maximum use temperature of the Ti-15-3 alloy), this system was selected for use in the NASA/P\&W cooperative program because of availability, established processing parameters, and reproducability of mechanical properties. Isothermal fatigue behaviors of the $\left[0^{\circ}\right],\left[90^{\circ}\right]$, and unreinforced systems were investigated at a temperature of $427^{\circ} \mathrm{C}$. This was the temperature selected for the static burst and fatigue tests on the TMC rings. To examine the effects of cut/exposed fibers on the coupon edges and more closely approximate conditions found in the MMC ring, clad $\left[0^{\circ}\right]$ specimens were also fabricated and tested. In addition, the thermomechanical fatigue (TMF) behaviors of the $\left[0^{\circ}\right]$ and $\left[90^{\circ}\right]$ systems were examined. Failure and damage mechanisms exhibited by the various coupons and cycle types were compared and contrasted through the use of optical and scanning electron microscopy (SEM) fractography and metallography.

\section{MATERIAL DETAILS}

The SCS-6/Ti-15-3 composite consisted of Ti-15V-3Cr-3Al-3Sn (weight percent) alloy matrix reinforced with approximately $35 \mathrm{vol} \%$ of continuous SiC (SCS-6) fibers. The SCS-6 fiber has a nominal diameter of $140 \mu \mathrm{m}$. All composite test specimens were obtained from eight and nine ply unidirectionally reinforced panels fabricated by HIPing alternate layers of Ti-15-3 foil and SCS-6 fiber mat. The resulting panel thicknesses were approximately $2 \mathrm{~mm}$. An unreinforced Ti-15-3 alloy panel was also fabricated using Ti-15-3 foils and the same consolidation process and parameters employed in composite production.

Coupon test specimens with a nominal geometry of 15.2 by $1.3 \mathrm{~cm}$ were cut from the composite panels parallel to (i.e., $\left[0^{\circ}\right]$ ), and perpendicular to (i.e., $\left[90^{\circ}\right]$ ), the fiber direction by means of wire electrodischarge machining (EDM). The heat-effected zone was removed by diamond wheel grinding the machined edges. After machining, the specimens were heat treated at $700{ }^{\circ} \mathrm{C}$ for $24 \mathrm{hr}$ in vacuum to stabilize the microstructure of the matrix. Note that because the specimens were cut out of large, flat panels, the machined edges exhibited cut/exposed fiber ends which may influence the specimen's fatigue life.

Given that the NASA/P\&W ring design consisted of a TMC ring embedded within an outer matrix cladding and did not have cut/exposed fibers, there was some concern as to the appropriateness and applicability of testing TMC coupons with cut/exposed fibers. Therefore, $[0]_{8}$ clad composite coupon-size panels without cut/exposed fibers were also fabricated. These clad composite test specimens were fabricated from Ti-15-3 foils, 20 by $2.5 \mathrm{~cm}$, and SCS- 6 fiber mats, 20 by $1.2 \mathrm{~cm}$. Extra Ti-15-3 foil sheets were added to the top and bottom faces of the panels. These coupon-size panels were then consolidated using the same consolidation process employed for the larger panels. Clad specimens were machined from these panels such that the machined edges in the gage section would not intersect any fibers. After machining, the specimens were heat treated at $700{ }^{\circ} \mathrm{C}$ for $24 \mathrm{hr}$ in vacuum. The actual fiber distribution and Ti-15-3 case of a clad test specimen are shown in figure 1. Note that the TMC core had a fiber content of approximately 35 vol \% (identical to the unclad composite), and the thickness of the Ti-15-3 case was approximately $0.5 \mathrm{~mm}$ on the broad face and 1 to $2 \mathrm{~mm}$ on the edge. The overall fiber content of the clad specimens was 19 to 21 vol \%.

Cylindrical test specimens, with a 4.8-mm diameter in the gage section, were used to characterize the unreinforced Ti-15-3 alloy. This specimen design was selected (over the flat-plate design) to accommodate 
the compressive loads anticipated in the strain-controlled fatigue tests. These specimens were also heat treated at $700{ }^{\circ} \mathrm{C}$ for $24 \mathrm{hr}$ in vacuum after machining.

\section{TEST DETAILS}

All fatigue tests were conducted with servo-hydraulic test systems equipped with either hydraulic wedge or collet style grips. The composite testing employed zero-tension (i.e., $R_{\sigma}=0$ ), load-controlled triangular waveforms with the exception of the $[0]_{9}$ TMF where a sine waveform was used; the zerotension cycle was selected to prevent specimen buckling problems with the thin-plate composite coupon specimens. Axial strain measurements were made with a high temperature extensometer mounted on the edge of the specimen. Direct induction heating was used for all composite testing.

The isothermal composite tests were conducted at $427^{\circ} \mathrm{C}$ with a cyclic load frequency of $3.3 \times 10^{-1} \mathrm{~Hz}$. A number of $[90]_{8}$ specimens were also tested with a frequency of $8.3 \times 10^{-3} \mathrm{~Hz}$ to match that used for the $[90]_{8}$ TMF tests; this was done to help balance the isothermal and TMF cycles with respect to the effects of environmental degradation and time-dependent phenomena. In-phase (IP) and out-of-phase (OP) TMF tests were conducted on the $[0]_{9}$ and $[90]_{8}$ systems. IP and OP loadings are defined as a $0^{\circ}$ (IP), and $90^{\circ}$ (OP), time phase shift between the load and temperature waveforms. A temperature cycle of 93 to $538^{\circ} \mathrm{C}$ was used for the $[0]_{9}$ TMF tests with a cyclic frequency of $5.6 \times 10^{-3} \mathrm{~Hz}$. The $[90]_{8}$ TMF tests employed a temperature cycle of 200 to $427^{\circ} \mathrm{C}$ with a cyclic frequency of $8.3 \times 10^{-3} \mathrm{~Hz}$.

Isothermal fatigue tests on the unreinforced Ti-15-3 alloy were conducted at $427^{\circ} \mathrm{C}$ using a straincontrolled command waveform. While strain-controlled testing of the unreinforced Ti-15-3 may seem inappropriate as a comparison to the load-controlled composite tests, this choice is not without merit, as matrix deformation in the composite is very much a strain-limited condition resulting from the stiff elastic response of the fibers. As with the isothermal composite tests, a $3.3 \times 10^{-1} \mathrm{~Hz}$ triangular command waveform was employed. For these strain-controlled tests, a $\min / \max$ strain ratio of zero (i.e., $\mathrm{R}_{\varepsilon}=0$ ) was selected to represent matrix behavior in the composite. Furnace heating was used on the unreinforced specimens.

\section{RESULTS AND DISCUSSION}

\section{Tensile Behavior}

Before examining the fatigue behavior of the composite and unreinforced Ti-15-3 alloy, it is instructive to examine the tensile properties summarized in table I. As expected the modulus and strength of the $[0]_{8}$ composite are superior to that of the unreinforced Ti-15-3 alloy and the $[90]_{8}$ composite, but the failure strain is quite low, reflecting the brittle nature of the SCS-6 fibers. For the $[90]_{8}$ composite, the initial modulus is significantly greater than that of the unreinforced Ti-15-3 alloy; however, the yield strength (proportional limit), tensile strength, and elongation of the $[90]_{8}$ composite are far less than that of the unreinforced Ti-15-3 alloy. These low numbers for the $[90]_{8}$ composite have been attributed to the weakness of the fiber-matrix interface (refs. 1 to 3 ).

\section{Deformation Behavior}

During isothermal fatigue testing of composite and unreinforced Ti-15-3 alloy at $427^{\circ} \mathrm{C}$, notable differences in deformation behavior were observed. These fatigue data are summarized in table II. For the 
unreinforced Ti-15-3 alloy, strain-controlled testing produced significant changes in mean stress. At the start of the test, a zero-tension stress situation prevailed, but by half-life $\left(0.5 \mathrm{~N}_{\mathrm{f}}\right)$ a balanced tensioncompression stress condition was established. This drop in mean stress was produced by plastic flow and stress relaxation.

For the load-controlled fatigue tests on composites, changes in strain response were observed and are typified in figure 2. In general, little or no change in strain range, and therefore compliance, was observed for the $[0]_{8}$ composite and the stress-strain response for any given cycle was nominally linear. At much higher stress levels and/or temperatures above $427^{\circ} \mathrm{C}$ (not reported here), the mean strain response has been observed to increase significantly during initial loading cycles (ref. 4). Later in the cyclic life, the $[0]_{8}$ composite revealed some increase in peak strain, as shown in figure 2 . This increase has been attributed to a combination of load shedding from the matrix to the fibers brought about by stress relaxation of the matrix and the accumulation of damage by way of crack initiation and propagation (ref. 4). Fractography and metallography of the $[0]_{8}$ specimens revealed multiple internal crack initiation sites at fiber/matrix $(\mathrm{F} / \mathrm{M})$ interfaces. Cracks were also found to originate from surface locations. Individual cracks typically propagated a distance of 1 to 2 fiber diameters before coalescing.

For the $[90]_{8}$ composite, a nonlinear stress-strain response, such as that shown in figure 3 , was observed for cyclic stress ranges greater than approximately $140 \mathrm{MPa}$. This nonlinear response results predominantly from F/M debonding, and with increasing stress, plastic flow of the matrix (ref. 5). Significant increases in peak strain and strain range were observed with continued cycling for all stress ranges. These increases are believed to be chiefly associated with additional F/M interface damage and propagation of fatigue cracks from the interfaces. It is also likely that matrix creep contributes to the strain accumulation. Fractography and metallography clearly revealed numerous oxidized fatigue cracks originating exclusively from F/M interface locations. The cut/exposed SCS-6 fibers on the machined edges of the coupon appear to enhance internal oxidation by serving as conduits for oxygen transportation.

\section{Isothermal Fatigue Behavior}

The stress-based isothermal fatigue life comparison is given in figure 4 where the advantage of fiber direction reinforcement of the Ti-15-3 alloy becomes evident. In this comparison, fatigue life $\left(\mathrm{N}_{\mathrm{f}}\right)$ is plotted against maximum stress $\left(\mathrm{S}_{\max }\right)$; the $\mathrm{S}_{\max }$ at $0.5 \mathrm{~N}_{\mathrm{f}}$ was used for the unreinforced Ti-15-3 strain controlled tests. The $[0]_{8}$ composite had the longest life, followed by the unreinforced Ti-15-3 alloy, and lastly the $[90]_{8}$ composite. Note that for the unreinforced Ti-15-3 alloy the stress range would be double that shown as a balanced tension-compression stress condition existed at $0.5 \mathrm{~N}_{\mathrm{f}}$. The exceptionally low life of the $[90]_{8}$ composite was clearly a function of a number of identified processes, including fiber-matrix debonding, strain ratchetting brought about by matrix creep, and environmental effects associated with interface oxidation of exposed fibers. To help sort out these effects, a comparison of the $[90]_{8}$ composite data run at $3.3 \times 10^{-1} \mathrm{~Hz}$ and $8.3 \times 10^{-3} \mathrm{~Hz}$ is instructive. If environmental degradation and/or strain ratchetting effects were distinctively dominant, then the specimens loaded at the lower frequency should have exhibited shorter lives, given that the exposure times per cycle were significantly greater (120 versus $3 \mathrm{sec}$ ) and loading rates were greatly reduced. Such trends have been clearly evidenced in the $\left[0^{\circ}\right]$ system (ref. 6). However, figure 4 shows that the cyclic lives of specimens loaded at the two frequencies were essentially equivalent, strongly suggesting that the weak $\mathrm{F} / \mathrm{M}$ bond was predominantly responsible for the short lives of the $[90]_{8}$ composite. This conclusion is also supported by the fractography and metallography noted above which revealed that all observable cracks initiated at F/M interfaces.

Returning to the discussion of isothermal tests conducted in the fiber direction, one sees that adding a Ti-15-3 cladding to the $[0]_{8}$ composite diminished fatigue lives on a stress basis. This was anticipated 
given that the overall fiber volume percent is lower for the clad composite specimens, even though the composite core had the same fiber content as the unclad specimens. To normalize these results, a strainbased fatigue life plot is presented in figure 5, where strain range $(\Delta \varepsilon)$ at $0.5 \mathrm{~N}_{\mathrm{f}}$ is plotted against fatigue life. The $\Delta \varepsilon$ versus $\mathrm{N}_{\mathrm{f}}$ plot reveals that the lives of the clad and unclad $[0]_{8}$ composites were equivalent at higher strain ranges, but the clad composite specimens had shorter lives at lower strain ranges. Examination of fracture surfaces of the clad specimens provided insight to help explain this life deficit. At higher strain ranges, fatigue initiation sites were found in both the Ti-15-3 case and the composite core, and in general, the cracks which initiated in the Ti-15-3 case did not have sufficient time to propagate into the composite core before failure occurred. Thus, internal core crack initiation/propagation was the primary failure mechanism, identical to that observed in tests on composite without the Ti-15-3 case. In contrast, at low strain ranges numerous fatigue cracks initiated at the surface of the Ti-15-3 case and had sufficient time to propagate into the composite core (fig. 6). The composite core was essentially free of internal crack initiation sites. These case initiated cracks may have accelerated crack propagation in the composite core by producing a larger crack which resulted in a higher stress intensity at the crack tip. This increased stress intensity would be more likely to cause fiber failure when the crack front reached the composite core.

The $\Delta \varepsilon$ versus $\mathrm{N}_{\mathrm{f}}$ plot shown in figure 5 also reveals that the $[90]_{8}$ composite continues to exhibit inferior fatigue life properties, analogous to trends established in the $S_{\max }$ versus $N_{f}$ plot (fig. 4). However, in contrast to the $S_{\max }$ versus $N_{f}$ trends, the strain-based plot reveals that the unreinforced Ti-15-3 alloy exhibits a significant life advantage in comparison to the $[0]_{8}$ composite. It is reasonable that this may be due in part to the vast differences in the mechanisms affecting crack initiation and propagation. At cyclic strain ranges of less than 1 percent, crack initiation is a relatively long process for the ductile unreinforced Ti-15-3 alloy. However, for the $[0]_{8}$ composite, previous work (ref. 6) has shown that crack initiation occurs rapidly and most of the isothermal fatigue life is consumed during the propagation of matrix cracks. Further, at $427^{\circ} \mathrm{C}$, there are multiple initiation sites throughout the cross section of the $[0]_{8}$ composite, generally at the relatively brittle, F/M interfaces. Taken in combination (i.e., the accelerated initiation of fatigue cracks at numerous $\mathrm{F} / \mathrm{M}$ interfaces throughout the composite) and considering both the strain limitations of the SCS- 6 fiber $\left(\varepsilon_{\mathrm{f}}<1\right.$ percent $)$ and the imposed zero-tension cycle, it is reasonable that the fatigue life of unreinforced Ti-15-3 alloy is superior to that of $[0]_{8}$ composite on a strain basis.

\section{Thermomechanical Fatigue Behavior}

Fatigue life results from the $[0]_{9}$ TMF tests (ref. 7) are plotted in figure 7 on a stress basis along with a linear regression fit of the isothermal fatigue data generated at $427^{\circ} \mathrm{C}$. The TMF data are also tabulated in table III. Recall that the temperature cycle for the $[0]_{9}$ TMF tests was 93 to $538^{\circ} \mathrm{C}$. Given that the $\mathrm{T}_{\max }$ for the TMF was $538^{\circ} \mathrm{C}$ and the isothermal data was generated at $427^{\circ} \mathrm{C}$, additional isothermal data generated at $550^{\circ} \mathrm{C}$ (ref. 4) are also included to better facilitate comparisons between isothermal and TMF conditions. In general, cyclic lives determined under TMF conditions were greatly reduced from those obtained under comparable isothermal conditions. Note that the IP and OP curves cross at a $\mathrm{S}_{\max }$ of approximately $750 \mathrm{MPa}$, above which the IP conditions are life limiting and below which OP conditions appear to be more damaging. Three factors were identified as dominating the damage and failure mechanisms in the TMF tests, namely, environmental degradation, factors leading to enhanced strain ratchetting, and a coefficient of thermal expansion (CTE) mismatch effect.

A CTE mismatch effect is present in many brittle/ductile composite systems because of the widely differing properties of the fiber and the matrix. Given that the CTE of the Ti-15-3 matrix $\left(\alpha_{\mathrm{m}} \simeq 9.0 \times 10^{-6}{ }^{\circ} \mathrm{C}^{-1}\right.$ (ref. 8)) is more than twice that of the SCS-6 fiber $\left(\alpha_{\mathrm{f}} \simeq 4.0 \times 10^{-6}{ }^{\circ} \mathrm{C}^{-1}\right.$ (ref. 9)), internal stresses 
(tensile in the matrix and compressive in the fiber) are generated as the composite cools from elevated temperatures to room temperature. Work performed by Gabb et al. (ref. 4) on this TMC system revealed that specimens subjected to 10000 thermal cycles (from 300 to $550{ }^{\circ} \mathrm{C}$ ) under zero load did not exhibit degraded mechanical responses during subsequent tests. However, the CTE mismatch did promote highly localized cracks in the reaction zone and carbon-rich coating of the fibers. TMF conditions combine this cyclic CTE mismatch effect with the effects of mechanical loading, potentially enhancing the overall progression of damage in the composite.

In-phase, zero-tension TMF (maximum load at maximum temperature) loading introduces conditions which are highly conducive to strain-ratchetting. This effect is amplified over that produced under zerotension isothermal conditions because of the increasing elastic modulus and yield strength of the matrix (due to the decreasing temperature) during unload. Here, the "cold" nominally elastic unload reduces the degree of strain reversal, in turn enhancing the tensile strain ratchetting effects associated with the matrix load shedding cited above. This effect is evidenced in figure 8 where the mechanical strain (total strain minus initial thermal strain) response from representative $[0]_{9}$ IP and OP TMF tests are shown. IP loadings produced notable increases in peak strain during initial loading cycles. Subsequently, the peak strain appeared to stabilize exhibiting minimal or no detectable increases prior to failure; individual hysteresis loops were nominally linear. Also note that the strain range did not exhibit an increase, suggesting no change in the material's compliance. Fractography and metallography indicated that the IP damage and failure mechanisms were dissimilar to those revealed under isothermal and OP conditions. Fractographs revealed extensive fiber pull-out and ductile matrix failure across the entire fracture surface. These features were very similar to those displayed by specimens subjected to tensile tests (ref. 10), suggesting pure tensile overload failures in the IP tests. Metallographic sections clearly revealed extensive fiber damage in the absence of matrix cracking, where fiber cracking was found to occur in both the transverse (more predominant) and longitudinal directions. This observation of excessive fiber cracking is compatible with the fact that in an IP TMF test, the longitudinal CTE mismatch stresses combine with the mechanical loading stresses so as to produce a relative increase in the fiber stress range.

In contrast to IP loadings, OP loadings did not promote initial excessive strain ratchetting, as OP maximum loading occurs at the minimum temperature where matrix load shedding and tensile strain ratchetting is not likely to occur. The strain response revealed only minor increases in peak strain at the onset of the test. Subsequently, a very gradual decreasing trend in peak strain was consistently detected in the OP tests as a possible result of a degrading composite CTE. Matrix work hardening and/or the hardening effects associated with the precipitation of additional $\alpha$-Ti phase may also have contributed to this decrease. Later in cyclic life $\left(\mathrm{N}>0.7 \mathrm{~N}_{\mathrm{f}}\right)$ the OP specimens displayed substantial increases in peak strain and strain range (i.e., an increase in compliance), indicating damage accumulation. Fracture surfaces revealed flat fatigue cracks which initiated almost exclusively at surface and near-surface F/M interface locations. This perimeter of oxidized fatigue cracking (approximately two to three fibers into the cross section) surrounded an internal region which exhibited ductile matrix failure and fiber pull-out indicative of tensile overload failure. Metallographic sections revealed that the primary cyclic fatigue damage consisted of matrix cracks normal to the load, initiated from surface and near-surface F/M interface locations. Little if any fiber damage was visible away from the fracture surface. This observation of excessive matrix damage is compatible with the fact that in an OP TMF test, the longitudinal CTE mismatch stresses combine with the mechanical loading stresses so as to produce a relative increase in the matrix stress range.

The results for the $[90]_{8}$ composite TMF tests with a temperature cycle of 200 to $427^{\circ} \mathrm{C}$ are tabulated in table III and plotted on a stress basis in figure 9 , along with the $427^{\circ} \mathrm{C}[90]_{8}$ isothermal data. The lives resulting from IP TMF were very similar to those produced under isothermal conditions at the maximum temperature of $427^{\circ} \mathrm{C}$. In fact, given the zero-tension loading conditions investigated, the isothermal cycle 
appears to be slightly more damaging at the higher stress levels. However, the comparative lives exhibited under OP TMF conditions are consistently greater by approximately an order of magnitude. These trends are obviously not consistent with those established by the $[0]_{9}$ TMF results, indicating that the TMF damage mechanisms have changed. Many of the mechanisms leading to reduced $[0]_{9}$ TMF lives relative to isothermal lives are either nonexistent or may be rendered ineffectual in the $[90]_{8}$ system by the extremely weak F/M bond. Given that the F/M bond normal to the load direction is lost after the first cycle, $[0]_{9}$ TMF mechanisms associated with load shedding from the matrix to the fiber and CTE mismatch effects likely become inconsequential.

Mechanical strain responses are shown in figure 10 for IP and OP $[90]_{8}$ TMF tests with $\mathrm{S}_{\max }=150 \mathrm{MPa}$. The first-cycle damage (i.e., stiffness degradation) was comparable for both the IP and OP loadings. However, the IP tests experienced a much higher rate of both strain ratchetting and stiffness degradation as evidenced in figure 10. The IP tests experienced strain ratchetting effects comparable to, but slightly less than those typically observed during $427^{\circ} \mathrm{C}$ isothermal loadings with a loading frequency of $8.3 \times 10^{-3} \mathrm{~Hz}$. It is also worthy to note that for equivalent values of $\mathrm{S}_{\max }$, the $427^{\circ} \mathrm{C}$ isothermal loading produced much greater first cycle damage than that produced under IP TMF conditions (ref. 11). For example, with a $\mathrm{S}_{\max }$ of $150 \mathrm{MPa}$, the first cycle stiffness degradation was approximately 10 percent for the IP TMF, but greater than 30 percent for the isothermal.

Optical and SEM fractography confirmed the commonality in failure mechanisms between the $427^{\circ} \mathrm{C}$ isothermal, IP TMF, and OP TMF. All TMF $[90]_{8}$ fractographs revealed exclusive internal crack initiation at $\mathrm{F} / \mathrm{M}$ interface locations. Oxidized $\mathrm{F} / \mathrm{M}$ interface damage and propagation of the fatigue cracks from the interfaces were identical to those described above for the isothermal tests. Again, the damage mechanisms appear to be dominated by effects associated with the weak $\mathrm{F} / \mathrm{M}$ interfaces and the exposed fiber ends serving as oxygen "pipelines" to the numerous internal cracks.

\section{SUMMARY OF RESULTS}

A comprehensive coupon level experimental investigation was conducted on unidirectionally reinforced SCS-6/Ti-15-3. This work was conducted to generate a self-consistent data base in support of a TMC life prediction modeling effort ultimately aimed at predicting the burst strength and fatigue life of advanced TMC disks. This data was used for purposes of model development, characterization, and verification. The $427^{\circ} \mathrm{C}$ isothermal fatigue and TMF behavior of the $\left[0^{\circ}\right]$ and $\left[90^{\circ}\right]$ systems were studied with emphasis placed on characterizing the key damage mechanisms. The following results were obtained:

(1) The $427{ }^{\circ} \mathrm{C}$ isothermal fatigue behavior of the $\left[0^{\circ}\right]$ TMC revealed significant strength and fatigue life improvements over the unreinforced Ti-15-3 matrix. However, this was only concluded on a stress based comparison, and was not the case on a strain based comparison. Environmentally enhanced cracking was found to initiate at internal fiber/matrix (F/M) interfaces and surface locations.

(2) Encasing the $\left[0^{\circ}\right]$ TMC with a Ti-15-3 case did not affect isothermal fatigue lives at higher strain levels where numerous small core initiated cracks were found to predominate. In contrast, at lower strain levels, large fatigue cracks were found to initiate at the external surface of the case and propagate into the core, degrading the fatigue lives relative to the unclad material.

(3) The 93 to $538^{\circ} \mathrm{C}\left[0^{\circ}\right]$ TMF lives were significantly reduced when compared to $\mathrm{T}_{\max }$ isothermal lives. At high strains, in-phase TMF produced extremely short lives. This degradation was attributed to fiber overload failures brought about by stress relaxation in the matrix. Metallography revealed a high degree of fiber cracking with no matrix fatigue cracking evident. At low strains, out-of-phase TMF 
conditions became life-limiting. Environment-assisted surface cracking was found to accelerate fatigue failure. Here, extensive matrix fatigue damage was observed with minimal fiber damage.

(4) The $427^{\circ} \mathrm{C}$ isothermal fatigue behavior of the $\left[90^{\circ}\right]$ TMC exhibited significantly degraded fatigue properties in comparison to that of both the $\left[0^{\circ}\right]$ system and unreinforced Ti-15-3 matrix; this was evidenced on both stress and strain based life comparisons. The poor fatigue properties were primarily attributed to the weak F/M interfacial bond. Fractography and metallography revealed numerous crack initiation sites exclusively at F/M interface locations. Environmental degradation was also enhanced by oxygen diffusion down exposed fiber ends.

(5) The 200 to $427^{\circ} \mathrm{C}\left[90^{\circ}\right]$ TMF conditions did not promote an additional degradation in cyclic life beyond that observed under $\mathrm{T}_{\max }$ isothermal conditions. In-phase lives were essentially identical to $427^{\circ} \mathrm{C}$ isothermal lives and out-of-phase lives were typically an order of magnitude greater. Based on relative stiffness degradation, the isothermal cycle was more damaging. Fractography of the $\left[90^{\circ}\right]$ TMF specimens revealed damage mechanisms identical to those experienced under isothermal conditions.

Though much has been learned concerning the elevated fatigue damage mechanisms in unidirectional TMCs, it is worthwhile to note that several issues remain which need to be addressed. The most obvious of these include the effects of fully reversed loading, loading in a strain controlled environment, variation in fiber volume fraction, and multiaxial loadings. It is quite likely that each of these will have some influence on the fatigue damage mechanisms and resulting cyclic lives.

\section{CONCLUSIONS}

1. TMC fatigue behavior and damage mechanisms will vary with the direction of loading in components. Cyclic loads oriented at $90^{\circ}$ to the fiber reinforcement axis can degrade fatigue behavior due to accelerated damage.

2. Fatigue behavior and damage mechanisms can also vary with temperature conditions. TMF loading at $0^{\circ}$ to the fibers provides lower life than isothermal loading due to the activation of different damage mechanisms.

3. The provision of matrix encasements to surround TMC cores and prevent cut and exposed fibers will not necessarily improve the TMC fatigue resistance.

\section{REFERENCES}

1. Johnson, W.S.; Lubowski, S.J.; and Highsmith, A.L.: Mechanical Characterization of SCS-6/Ti-15-3 Metal Matrix Composites at Room Temperature. Thermal and Mechanical Behavior of Ceramic and Metal Matrix Composites, H.H. Moeller and W.S. Johnson, eds., ASTM, Philadelphia, 1990, pp. 193-218.

2. Gayda, J.; and Gabb, T.P.: Isothermal Fatigue Behavior of a $\left[90^{\circ}\right]_{8} \mathrm{SiC} / \mathrm{Ti}-15-3$ Composite at $426^{\circ} \mathrm{C}$. Int. J. of Fatigue, Jan. 1992, pp. 14-20.

3. Majumdar, B.S.; and Newaz, G.M.: Inelastic Deformation of Metal Matrix Composites: Part IPlasticity and Damage Mechanisms. NASA TM-189095, 1992. 
4. Gabb, T.P.; Gayda, J.; and MacKay, R.A.: Isothermal and Nonisothermal Fatigue Behavior of a Metal Matrix Composite. J. of Composite Mat., Vol. 24, June 1990, pp. 667-686.

5. Majumdar, B.S.; and Newaz, G.M.: Inelastic Deformation of Metal Matrix Composites: Plasticity and Damage Mechanisms-Part II. NASA TM-189096, 1992.

6. Gabb, T.P.; Gayda, J.; and MacKay, R.A.: Nonisothermal Fatigue Degradation of a SiC/Ti Composite. Advanced Composite Materials: Processing, Microstructures, Bulk, and Interfacial Properties, Characterization Methods, and Applications, M.D. Sacks, ed., American Ceramic Society, Westerville, OH, 1991, pp. 527-534.

7. Castelli, M.G.; Bartolotta, P.A.; and Ellis, J.R.: Thermomechanical Testing of High-Temperature Composites: Thermomechanical Fatigue Behavior of SiC(SCS-6)/Ti-15-3. Composite Materials: Testing and Design, G.C. Grimes, ed., ASTM, Philadelphia, 1992, pp. 70-86.

8. Rosenberg, H.W.: Ti-15-3 Property Data. Beta Titanium Alloys in the 80's, R.R. Boyer and H.W. Rosenberg, eds., TMS-AIME, Warrendale, PA, 1984, pp. 409-432.

9. Hillmer, N.J.: Thermal Expansion of High Modulus Fibers. Int. J. of Thermophysics, Vol. 12, No. 4, July 1991, pp. $741-750$.

10. Lerch, B.A.; and Saltsman, J.: Tensile Deformation Damage in SiC Reinforced Ti-15V-3Cr-3Al-3Sn. NASA TM-103620, 1991.

11. Castelli, M.G.: Thermomechanical Fatigue Behavior of a $[90]_{8}$ SCS-6/Ti-15-3 Composite. HITEMP Review 1992: Advanced High Temperature Engine Materials Technology Program, NASA CP-10104, vol. 2, Oct. 1992, pp. 52:1-14. (Available from the Center for AeroSpace Information as 93X10284.) 
TABLE I.-REPRESENTATIVE TENSILE PROPERTIES FOR SCS-6/Ti-15-3 AT $427^{\circ} \mathrm{C}$

\begin{tabular}{|l|c|c|c|c|}
\hline Material & $\begin{array}{c}\text { Elastic mod, } \\
\text { GPa }\end{array}$ & $\begin{array}{c}\text { Yield } \\
(0.2 \text { percent }), \\
\text { MPa }\end{array}$ & $\begin{array}{c}\text { UTS, } \\
\text { MPa }\end{array}$ & $\begin{array}{c}\text { Elongation, } \\
\text { percent }\end{array}$ \\
\hline$[0]_{8}$ & 195 & $-\ldots .-$ & 1510 & 0.88 \\
{$[90]_{8}$} & 110 & 240 & 325 & 1.48 \\
Ti-15-3 Matrix & 85 & 840 & 885 & 20.00 \\
\hline
\end{tabular}

TABLE II.-ISOTHERMAL FATIGUE DATA FOR SCS-6/Ti-15-3 AT $427^{\circ} \mathrm{C}$

\begin{tabular}{|c|c|c|c|c|c|c|}
\hline Material & $\begin{array}{l}\text { Life, } \\
\mathrm{N}_{\mathrm{f}}\end{array}$ & $\begin{array}{c}\mathrm{S}_{\max } \\
\mathrm{MPa}\end{array}$ & $\begin{array}{l}\mathrm{S}_{\min } \\
\mathrm{MPa}\end{array}$ & $\begin{array}{c}\Delta \varepsilon, \\
\text { percent }\end{array}$ & \begin{tabular}{|c} 
Frequency, \\
$\mathrm{Hz}$ \\
\end{tabular} & $\begin{array}{c}\text { Control } \\
\text { mode }\end{array}$ \\
\hline$[0]_{8}$ & $\begin{array}{rr}12 & 352 \\
17 & 599 \\
29 & 845 \\
2 & 669 \\
3 & 905 \\
5 & 769 \\
7 & 207 \\
17 & 522 \\
54 & 835\end{array}$ & \begin{tabular}{rr|}
1 & 034 \\
965 \\
\\
896 \\
1338 \\
1255 \\
1110 \\
1192 \\
972 \\
807
\end{tabular} & $\begin{array}{r}55 \\
48 \\
48 \\
0 \\
1\end{array}$ & $\begin{array}{r}0.57 \\
.49 \\
.48 \\
.70 \\
.69 \\
.60 \\
.59 \\
.54 \\
.44\end{array}$ & $\begin{array}{c}1.6 \times 10^{-1} \\
1.6 \times 10^{-1} \\
1.6 \times 10^{-1} \\
3.3 \times 10^{-1} \\
1\end{array}$ & Load \\
\hline${ }^{2}[90]_{8}$ & \begin{tabular}{rr|}
1 & 683 \\
3 & 603 \\
9 & 863 \\
166 \\
1179 \\
1340 \\
8874 \\
5265 \\
23643
\end{tabular} & $\begin{array}{l}172 \\
137 \\
110 \\
221 \\
172 \\
152 \\
138 \\
131 \\
110\end{array}$ & $\begin{array}{l}0 \\
1\end{array}$ & $\begin{array}{r}0.31 \\
.22 \\
.15 \\
.45 \\
.26 \\
.22 \\
.16 \\
.18 \\
.12 \\
\end{array}$ & $\begin{array}{c}3.3 \times 10^{-1} \\
3.3 \times 10^{-1} \\
3.3 \times 10^{-1} \\
8.3 \times 10^{-3} \\
!\end{array}$ & Load \\
\hline${ }^{b}$ Ti-15-3 matrix & $\begin{array}{rr}100 & 000+ \\
22 & 971 \\
2 & 150 \\
100 & 000+ \\
\end{array}$ & $\begin{array}{l}303 \\
428 \\
538 \\
407\end{array}$ & $\begin{array}{l}-290 \\
-434 \\
-559 \\
-393 \\
\end{array}$ & $\begin{array}{r}0.65 \\
1.00 \\
1.45 \\
.87 \\
\end{array}$ & $\left.\right|^{3.3 \times 10^{-1}}$ & $\stackrel{1}{\text { Strain }}$ \\
\hline${ }^{a} \mathrm{Clad}[0]_{8}$ & $\begin{array}{r}25619 \\
17027 \\
18314 \\
8783\end{array}$ & $\begin{array}{l}483 \\
552 \\
648 \\
793\end{array}$ & 0 & $\begin{array}{r}0.41 \\
.42 \\
.50 \\
.60\end{array}$ & $\begin{array}{c}3.3 \times 10^{-1} \\
!\end{array}$ & $\stackrel{\text { Load }}{1}$ \\
\hline
\end{tabular}

${ }^{\mathrm{a}} \Delta \varepsilon$ values taken at $0.5 \mathrm{~N}_{\mathrm{f}}$

${ }^{\mathrm{b}} \mathrm{S}_{\max }$ and $\mathrm{S}_{\min }$ values taken at $0.5 \mathrm{~N}_{\mathrm{f}}$. 
TABLE III.-THERMOMECHANICAL FATIGUE DATA

FOR SCS-6/Ti-15-3

\begin{tabular}{|c|c|c|c|c|c|}
\hline \multicolumn{3}{|c|}{$\begin{array}{c}{[0]_{9} 93 \text { to } 538^{\circ} \mathrm{C} \mathrm{TMF}} \\
\text { Frequency }=5.6 \times 10^{-3} \mathrm{~Hz} \\
\mathrm{~S}_{\min } \approx 0 \mathrm{MPa} ; \text { Load Control }\end{array}$} & \multicolumn{3}{|c|}{$\begin{array}{c}{[90]_{8} 200 \text { to } 427^{\circ} \mathrm{C} \mathrm{TMF}} \\
\text { Frequency }=8.3 \times 10^{-3} \mathrm{~Hz} \\
\mathrm{~S}_{\min } \approx 0 \mathrm{MPa} \text {; Load Control }\end{array}$} \\
\hline Phasing & $\begin{array}{l}\text { Life, } \\
\mathrm{N}_{\mathrm{f}}\end{array}$ & $\begin{array}{l}\mathrm{S}_{\max } \\
\mathrm{MPa}\end{array}$ & Phasing & $\begin{array}{l}\text { Life, } \\
N_{f}\end{array}$ & $\begin{array}{l}\mathrm{S}_{\max } \\
\mathrm{MPa}\end{array}$ \\
\hline IP & $\begin{array}{rrr} & & 1.5 \\
& & 1.5 \\
& 77 \\
& & 150 \\
1 & 072 \\
1 & 870 \\
1 & 177 \\
1 & 595 \\
25 & 820\end{array}$ & $\begin{array}{r}1034 \\
1034 \\
965 \\
965 \\
896 \\
896 \\
827 \\
827 \\
690\end{array}$ & IP & $\begin{array}{r}149 \\
354 \\
1455 \\
1617 \\
3440 \\
15938\end{array}$ & $\begin{array}{l}280 \\
220 \\
180 \\
150 \\
140 \\
130\end{array}$ \\
\hline OP & $\begin{array}{rr} & 801 \\
1 & 540 \\
1 & 178 \\
1 & 919 \\
2 & 954 \\
3 & 630 \\
4 & 333 \\
4 & 916 \\
7 & 145 \\
9 & 793\end{array}$ & $\begin{array}{r}1241 \\
1241 \\
1034 \\
1034 \\
896 \\
896 \\
827 \\
827 \\
690 \\
621\end{array}$ & OP & $\begin{array}{r}1013 \\
1585 \\
3435 \\
20938\end{array}$ & $\begin{array}{l}280 \\
250 \\
220 \\
150\end{array}$ \\
\hline
\end{tabular}

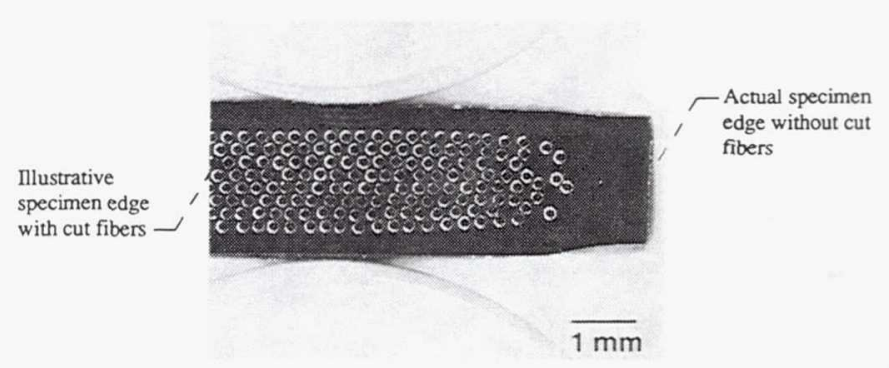

Figure 1.-Cross section of typical clad $[0]_{8}$ specimen. 


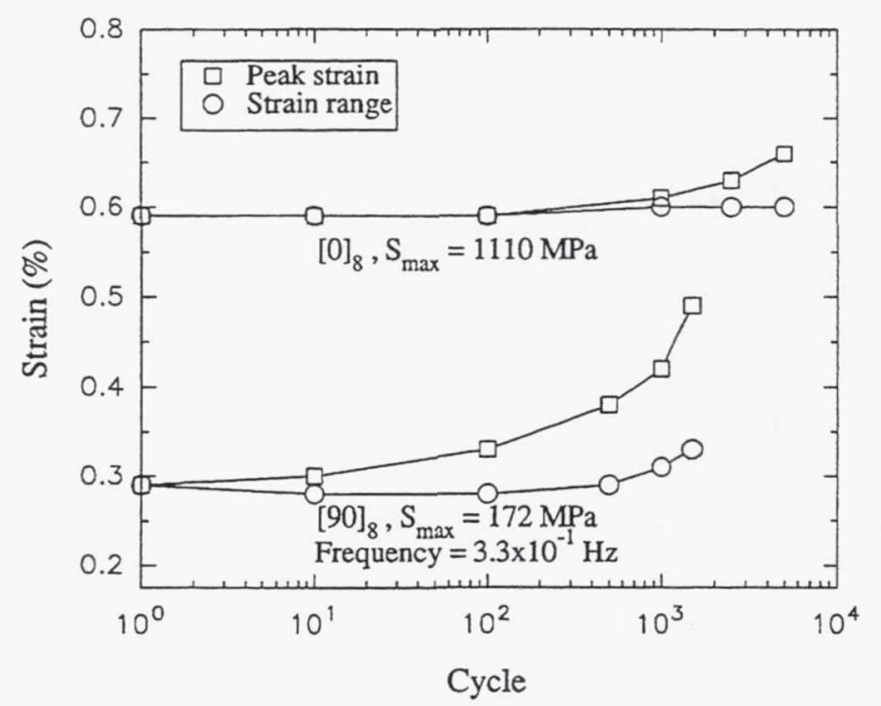

Figure 2. Changes in strain responses typical of $[0]_{8}$ and $[90]_{8}$ SCS-6/ Ti-15-3 during isothermal fatigue at $427^{\circ} \mathrm{C}$.

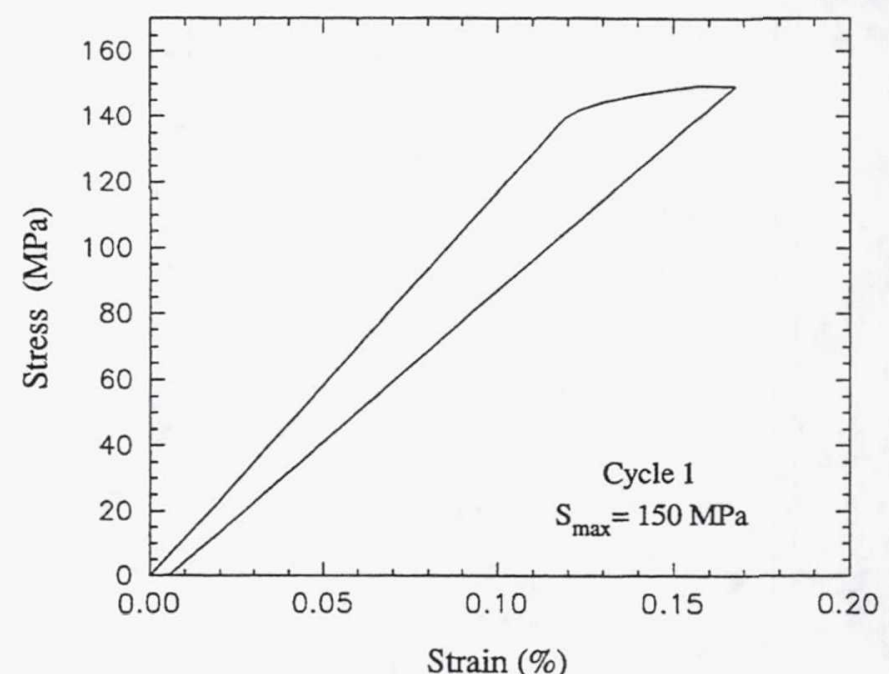
Figure 3. Representative cyclic deformation response of $[90]_{8}$
SCS-6/Ti-15-3 at $427^{\circ} \mathrm{C}$.

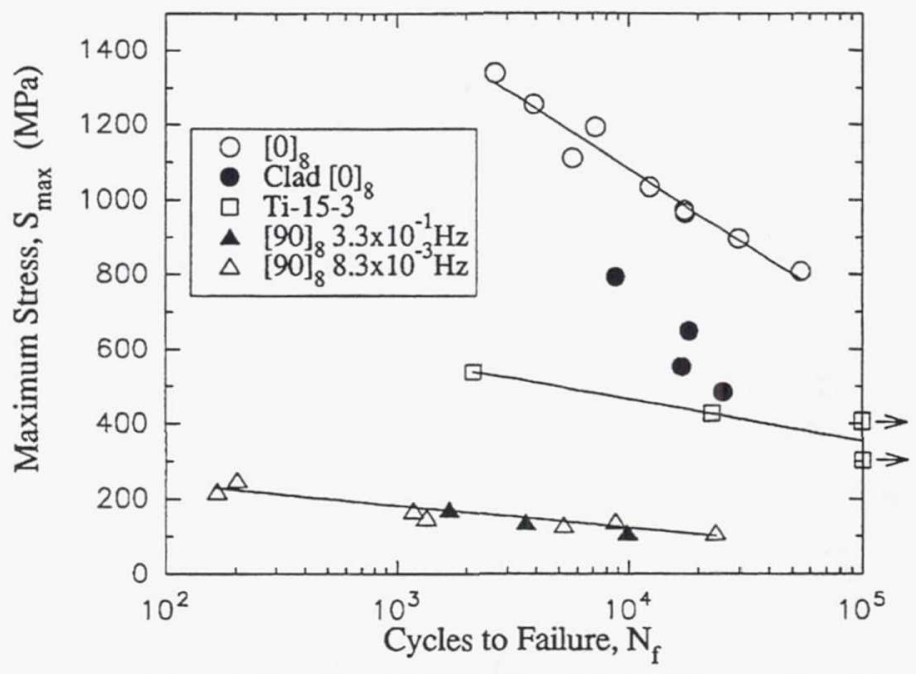

Figure 4. Stress-based $427^{\circ} \mathrm{C}$ isothermal fatigue life comparison for SCS-6/Ti-15-3.

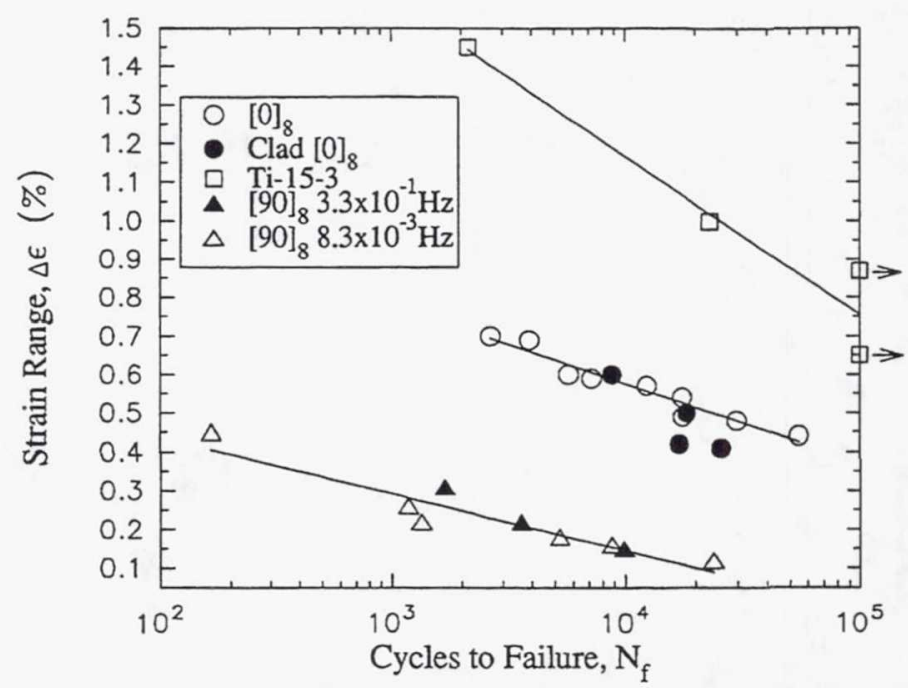

Figure 5. Strain-based $427^{\circ} \mathrm{C}$ isothermal fatigue life comparison for SCS-6/Ti-15-3. 

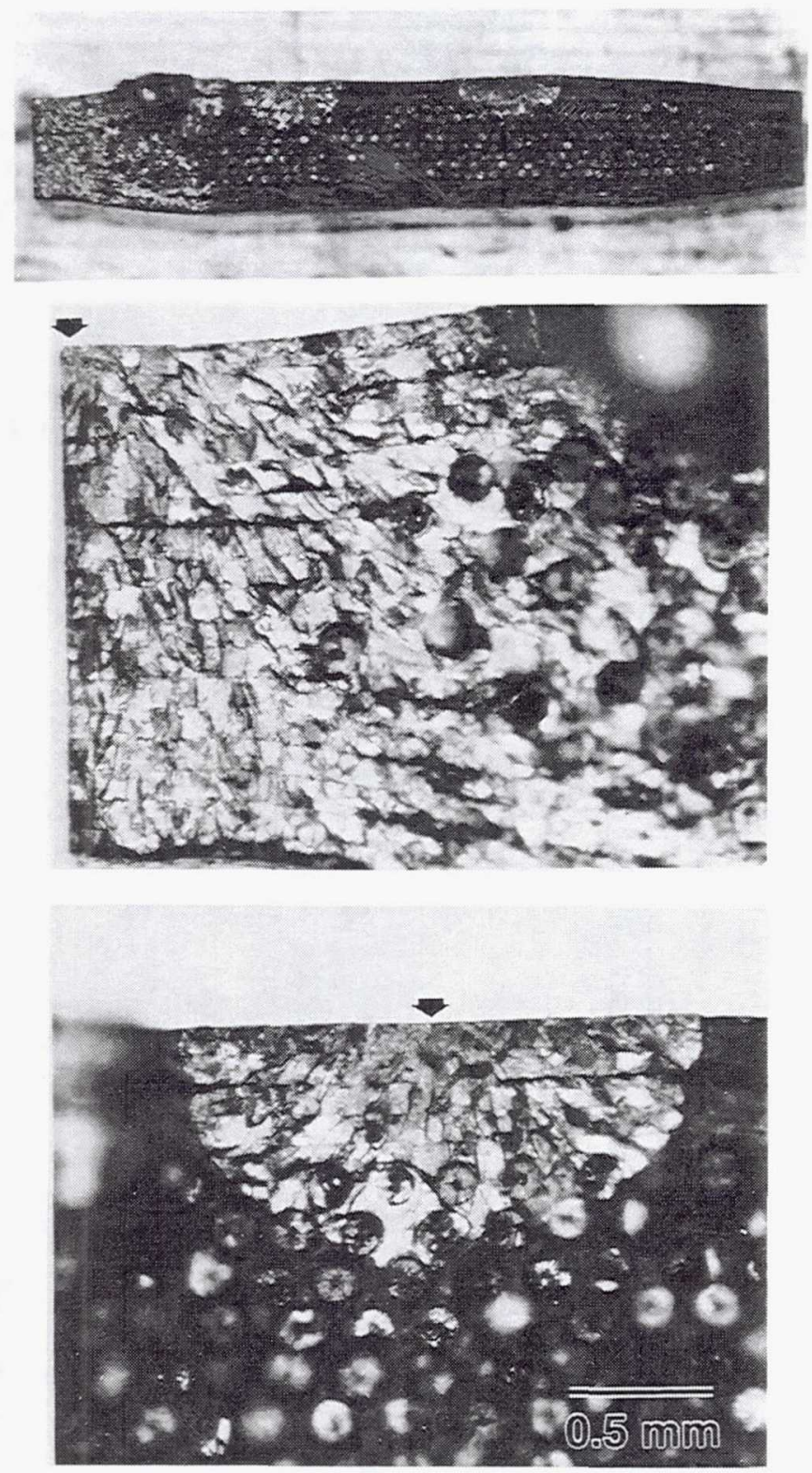

Figure 6.-Fracture surface of clad [0] ${ }_{8} \mathrm{SCS}-6 / \mathrm{Ti}-15-3$ specimen subjected to $427{ }^{\circ} \mathrm{C}$ isothermal fatigue at a low strain range. Cracks initiated in the Ti-15-3 case have propogated into the composite core.

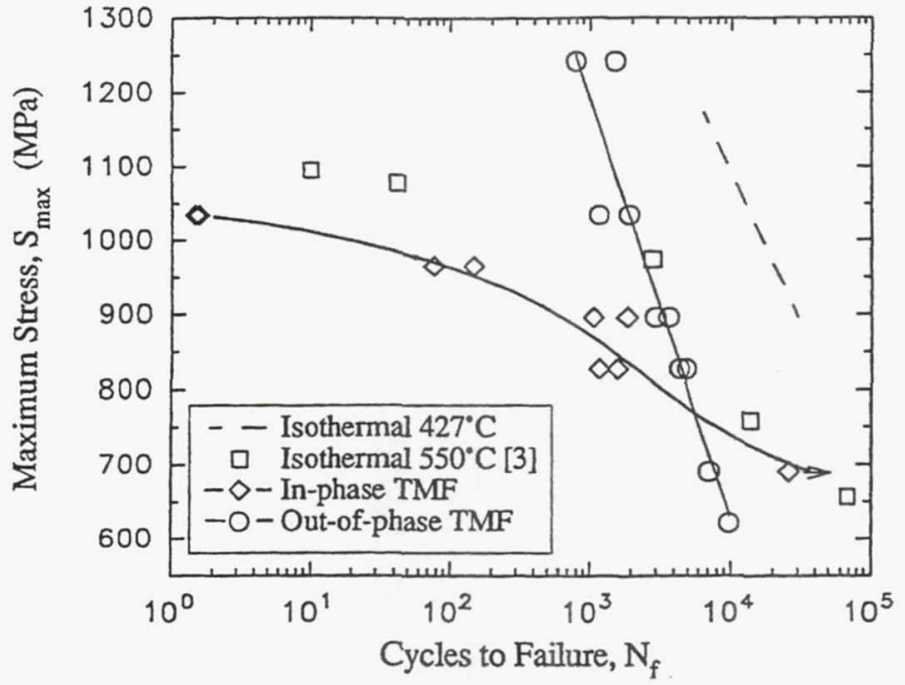

Figure 7. Thermomechanical fatigue behavior of $[0]_{9} \mathrm{SCS}-6 / \mathrm{Ti}-15-3$ with a temperature cycle of $93-538^{\circ} \mathrm{C}$ 


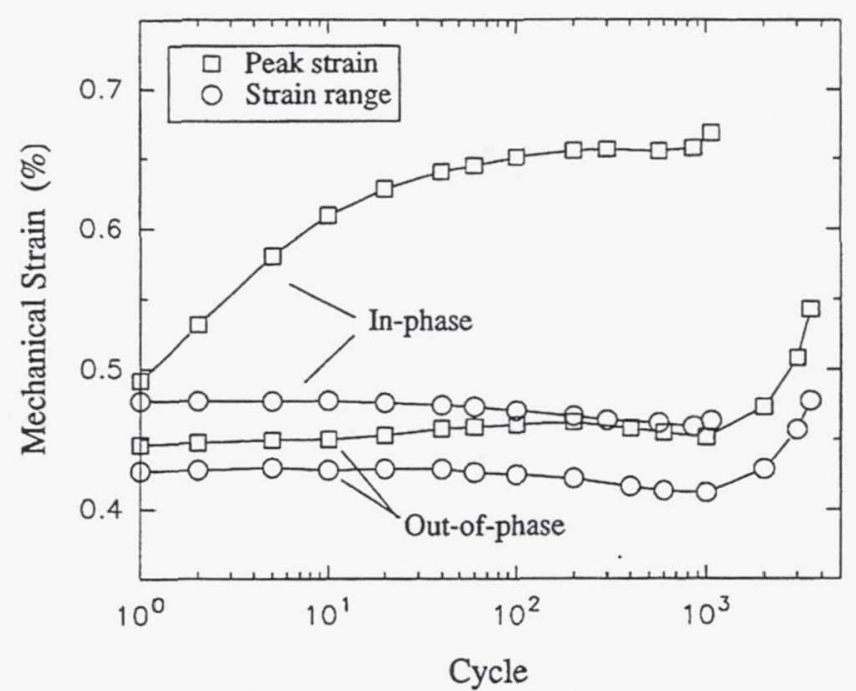

Figure 8. Changes in strain response of $[0]$, SCS-6/Ti-15-3 during in-phase and out-of-phase TMF with a temperature cycle of $93-538^{\circ} \mathrm{C}$ and $\mathrm{S}_{\max }=896 \mathrm{MPa}$.

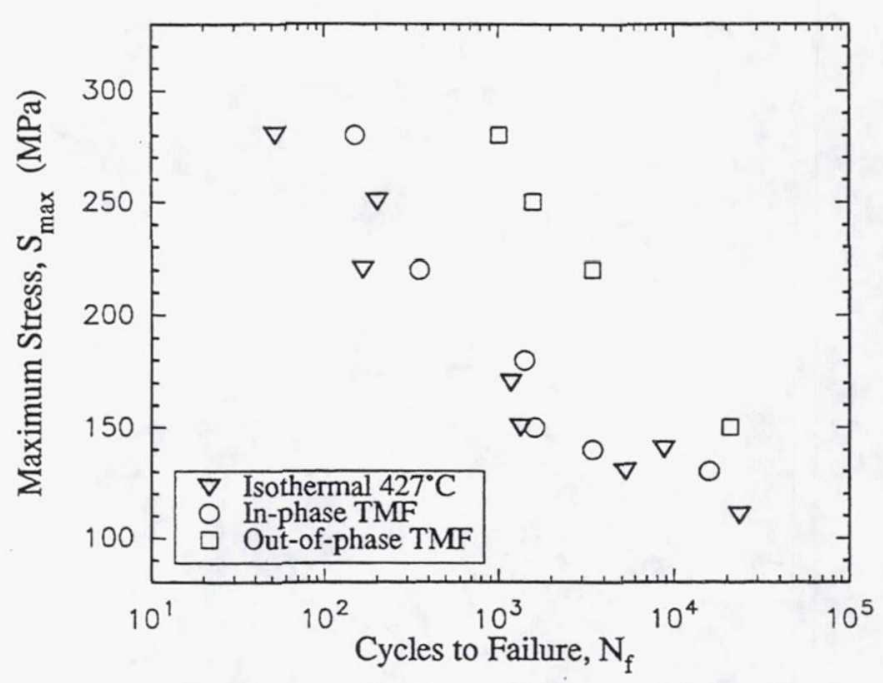

Figure 9. Thermomechanical fatigue behavior of $[90]_{8}$ SCS-6/Ti-15-3 with a temperature cycle of $200-427^{\circ} \mathrm{C}$.

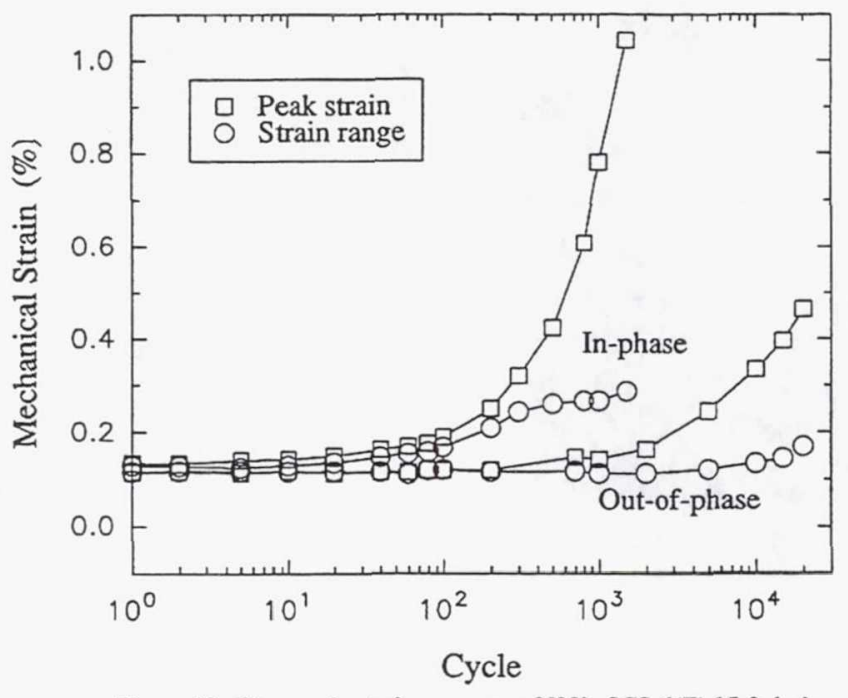

Figure 10. Changes in strain response of $[90]_{8}$ SCS-6/Ti-15-3 during in-phase and out-of-phase TMF with a temperature cycle of $200-427^{8} \mathrm{C}$ and $S_{\max }=150 \mathrm{MPa}$. 
Public reporting burden for this collection of information is estimated to average 1 hour per response, including the time for reviewing instructions, searching existing data sources, gathering and maintaining the data needed, and completing and reviewing the collection of information. Send comments regarding this burden estimate or any other aspect of this collection of information, including suggestions for reducing this burden, to Washington Headquarters Services, Directorate for Information Operations and Reports, 1215 Jefferson Davis Highway, Suite 1204, Arlington, VA 22202-4302, and to the Office of Management and Budget, Paperwork Reduction Project (0704-0188), Washington, DC 20503.

\begin{tabular}{|l|c|c|c|}
\hline 1. AGENCY USE ONLY (Leave blank) & $\begin{array}{c}\text { 2. REPORT DATE } \\
\text { April } 1993\end{array}$ & $\begin{array}{r}\text { 3. REPORT TYPE AND DATES COVERED } \\
\text { Technical Memorandum }\end{array}$ \\
\hline
\end{tabular}

4. TITLE AND SUBTITLE

5. FUNDING NUMBERS

An Overview of Elevated Temperature Damage Mechanisms and Fatigue

Behavior of a Unidirectional SCS-6/Ti-15-3 Composite

6. AUTHOR(S)

WU-510-06-50

Michael G. Castelli and John Gayda

7. PERFORMING ORGANIZATION NAME(S) AND ADDRESS(ES)

National Aeronautics and Space Administration

Lewis Research Center

Cleveland, Ohio 44135-3191

8. PERFORMING ORGANIZATION REPORT NUMBER

E-7729

9. SPONSORING/MONITORING AGENCY NAME(S) AND ADDRESS(ES)

10. SPONSORING/MONITORING AGENCY REPORT NUMBER

National Aeronautics and Space Administration

Washington, D.C. 20546-0001

NASA TM-106131

\section{SUPPLEMENTARY NOTES}

Prepared for the Tenth Biennial Conference on Reliability, Stress Analysis and Failure Prevention sponsored by the American Society of Mechanical Engineers, Albuquerque, New Mexico, September 19-22, 1993. Michael G. Castelli, Sverdrup Technology Inc., Lewis Research Center Group, 2001 Aerospace Parkway, Brook Park, Ohio 44142 and John Gayda, NASA Lewis Research Center. Responsible person, Michael G. Castelli, (216) 433-8464.

12a. DISTRIBUTION/AVAILABILITY STATEMENT

12b. DISTRIBUTION CODE

Unclassified - Unlimited

Subject Category 24

\section{ABSTRACT (Maximum 200 words)}

The fatigue behavior of a unidirectionally reinforced titanium matrix composite (TMC), SiC/Ti-15-3, was thoroughly characterized to support life prediction modeling of advanced TMC disks designed for gas turbine engine applications. The results of this coupon-level experimental investigation are reviewed in this paper. On a stress basis, the isothermal fatigue behavior of the $\left[0^{\circ}\right] \mathrm{TMC}$ revealed significant improvements over the unreinforced matrix. In contrast, the [ $\left.90^{\circ}\right]$ TMC exhibited degraded properties and lives for similar comparisons. This was attributed to the weak fiber/matrix interfacial bond. Encasing the $\left[0^{\circ}\right] \mathrm{TMC}$ with a Ti-15-3 case did not affect isothermal fatigue lives at higher strain levels. However, at lower strain levels, rapid initiation and propagation of large fatigue cracks in the case degraded the fatigue lives. Thermomechanical fatigue (TMF) lives were significantly reduced for the $\left[0^{\circ}\right] \mathrm{TMC}$ when compared to isothermal lives. At high strains, in-phase TMF produced extremely short lives. This degradation was attributed to fiber overload failures bought about by stress relaxation in the matrix. At low strains, out-of-phase TMF conditions became lifelimiting. Environment-assisted surface cracking was found to accelerate fatigue failure. This produced extensive matrix damage with minimal fiber damage. For the $\left[90^{\circ}\right] \mathrm{TMC}$, TMF conditions did not promote an additional degradation in cyclic life beyond that observed under isothermal conditions.

\section{SUBJECT TERMS}

Fatigue; Damage mechanisms; Titanium matrix composites; SCS-6/Ti-15-3

5. NUMBER OF PAGES

16

$$
\text { Fatigue; Damage mechanisms; Titanium matrix composites; SCS-6/Ti-15-3 }
$$

\begin{tabular}{|c|c|}
\hline $\begin{array}{c}\text { 17. SECURITY CLASSIFICATION } \\
\text { OF REPORT }\end{array}$ & $\begin{array}{c}\text { 18. SECURITY CLASSIFICATION } \\
\text { OF THIS PAGE } \\
\text { Unclassified }\end{array}$ \\
\begin{tabular}{c} 
Unclassified \\
\hline
\end{tabular}
\end{tabular}

19. SECURITY CLASSIFICATION OF ABSTRACT Unclassified

\section{E}

$\mathrm{A} 03$ 